\title{
Investigating trophic-level variability in Celtic Sea fish predators
}

\author{
E. CHASSOT ${ }^{1,{ }^{*}}$, T. ROUYER ${ }^{1,2}$, V. M. TRENKEL ${ }^{3}$ AND D. GASCUEL ${ }^{1}$
}

\author{
${ }^{1}$ Agrocampus Rennes, Pôle Halieutique, Laboratoire d'Ecologie Halieutique, 65 rue de St-Brieuc, C. S. 84215, \\ 35042 Rennes Cedex, France \\ 2 Ifremer, CRH, Avenue Jean Monnet, B. P. 171, 34203 Sète Cedex, France \\ ${ }^{3}$ Ifremer, Département EMH, B. P. 21105, 44311 Nantes Cedex 03, France \\ *: Corresponding author : Chassot E., Tel.: +33 4995732 24; fax: +33 4995732 95; email: \\ emmanuel.chassot@ird.fr
}

\begin{abstract}
:
The trophic level $\left(T_{L}\right)$ mean and variance, and the degree of omnivory for five Celtic Sea fish predators were estimated using a database of stomach content records characterized by a high level of taxonomic resolution. The predators occupied a high position in the food web, i.e. 4.75 for Atlantic cod Gadus morhua, 4.44 for haddock Melanogrammus aeglefinus, 4.88 for European hake Merluccius merluccius, 5.00 for megrim Lepidorhombus whiffiagonis and 5.27 for whiting Merlangius merlangus. The level of taxonomic resolution of the prey did not greatly affect mean $T_{L}$ predator values; an effect on variance was evident, low resolution masking intra-population variability in $T_{L}$. Generalized additive models (GAM) were used to explain the variability of predator $T_{L}$ caused by environmental variables (International Council for the Exploration of the Sea, ICES, division and season) and predator characteristics (total length, $\mathrm{L}_{T}$ ). Significant year, location season and interaction effects were found for some species and with $L_{T}$ at the scale of ICES subdivision. The species-specific variability of $T_{L}$ could be due to spatio-temporal variations in prey availability and in predator selectivity following ontogenetic changes. Omnivorous fish $T_{L}$ was less affected by spatio-temporal variations. In addition, results showed that the omnivory index and $T_{L}$ variability provide dissimilar information on predator feeding strategy. Combining information on $T_{L}$ variability and omnivory allowed between withinindividual and between-individual components contributing to trophic niche width to be separated and the type of generalization of fish predators to be identified.
\end{abstract}

Keywords: food web $\bullet \mathrm{GAM} \bullet$ indicator $\bullet$ omnivory $\bullet$ predation $\bullet$ trophic level 


\section{Introduction}

The trophic level $\left(T_{L}\right)$ reflects the position of an organism, species, population, or trophic group within the food web as it traces the path lengths for energy in an ecosystem (Lindeman, 1942). $T_{L}$ plays a major role in theoretical and applied ecology (Post, 2002; Williams \& Martinez, 2004) and appears relevant for an ecosystem approach to fisheries management (EAF; Garcia et al., 2003). In particular, $T_{L}$ constitutes the basis for the measurement of several indicators for evaluating the ecosystem effects of fishing (Pauly et al., 1998, 2000; Gascuel et al., 2005; Stergiou et al., 2007). Among the six trophodynamic indicators selected by Cury et al. (2005) in an EAF perspective, three are based on $T_{L}$ values: primary production required to support catches, mean $T_{L}$ of the catch and the Fishing-In-Balance index. In addition, the mean $T_{L}$ of the catch has been proposed as a measure of biodiversity, following the Conference of the Parties to the Convention on Biological Diversity (Pauly \& Watson, 2005). All these indicators are generally calculated based on mean $T_{L}$ values for each species that are either provided by FishBase, or derived from stomach content analyses or applications of Ecopath models (Christensen \& Pauly, 1992). Mean $T_{L}$ values, averaged over time and area, may conceal potentially high $T_{L}$ variability associated with food web dynamics (e.g. Greenstreet et al., 1997) and ontogenetic changes.

$T_{L}$ results from the predation process and depends on the combination of different factors that determine prey availability and vulnerability (Sih \& Christensen, 2001) including predator morphological and behavioural characteristics (Mérigoux \& Ponton, 1998; Karpouzi \& Stergiou, 2003). For a given species, diet composition has notably been shown to vary with time (Albert, 1995; Adlerstein \& Welleman, 2000), season (du Buit, 1995, 1996; Cabral \& Murta, 2002) and predator length through ontogenetic changes (Stergiou \& Karpouzi, 2002; Pinnegar et al., 2003). Hence, $T_{L} S$ are expected to display spatio-temporal variations according to fish age or length. In addition, estimates of $T_{L} S$ based on stomach content data rely on the $T_{L}$ values assigned to the prey and the level of taxonomic resolution of the prey. Therefore, it is important to study the relative contribution of different sources of variability of $T_{L}$ to understand how $T_{L}$-based indicators are sensitive to fish feeding behaviours and ecosystem characteristics in addition to fishing.

In the present analysis, the amount and sources of $T_{L}$ variability is investigated for a selection of representative predator fish species in the Celtic Sea, Atlantic cod (Gadus morhua L.), haddock (Melanogrammus aeglefinus L.), European hake (Merluccius merluccius L.), megrim (Lepidorhombus whiffiagonis W.) and whiting (Merlangius merlangus L.). The feeding habits of these five predator species greatly differ and they all have been shown to display, to varying extents, ontogenetic and/or spatio-temporal variations in diet (e.g. Hislop et al., 1991; Hop et al., 1992; Jiang \& Jorgensen, 1996; Morte et al., 1999; Carpentieri et al., 2005; Guichet 1995). Such changes might be reflected in their $T_{L}$ and omnivory.

This paper follows the works of Pinnegar et al. (2003) and Trenkel et al. (2005) who studied the relationships between prey availability and predator diets, and the spatio-temporal structure of predator-prey relationships in the Celtic Sea. The main outcome of the first analysis (Pinnegar et al., 2003) was that the diet of predator species changed as the animals grew larger, but generally did not reflect fish prey availability. This analysis provided evidence of the existence of interannual changes in prey importance and strong prey preferences in certain predators. By contrast, the results of the second study (Trenkel et al., 2005) suggested spatial and seasonal prey-switching behaviour by some fish predators and concluded that the Celtic Sea fish community is globally characterized by opportunistic predators and weak interspecific predator interactions. In the present study, knowledge of feeding relationships in the Celtic Sea was used to address the following objectives: (1) estimate the $T_{L}$ for the 5 predators and the corresponding $T_{L}$ variance, (2) investigate predator $T_{L}$ sensitivity to prey $T_{L}$ and level of taxonomic resolution, and (3) identify, quantify and order the factors that affect $T_{L}$ by species to better understand the sensitivity of this indicator to species ecological features and food web dynamics. 


\section{Material and methods}

\subsection{Stomach content data}

Fish stomachs were collected from 1981 to 1985 aboard nine French commercial trawlers during routine fishing operations in the Celtic Sea (Fig. 1). Samples were briefly investigated and only 'full' stomachs were preserved in seawater containing 10\% formalin (du Buit, 1982, 1992, 1995, 1996). Empty stomachs and those with partially regurgitated or unidentifiable contents were excluded. Time period (day, month, year), fishing depth $(\mathrm{m})$, and International Council for the Exploration of the Sea (ICES) subdivision where the fish were caught were recorded. Prey items were identified and sorted into taxonomic groups, to the species level whenever possible. The state of digestion of the prey was not considered in the analysis. For the selected dataset of stomachs, 57 prey taxa were identified at the species level, 32 were identified at the genus level and prey items that could not be identified beyond the sub-order level were pooled into broad taxonomic group levels, i.e. polychaete, echinoderm, cnidarian, cephalopod, mollusc (other than cephalopod), crustacean and fish. For each stomach, predator total length $(\mathrm{cm})$, prey number, prey identity and prey weight $(\mathrm{g})$ were recorded.

Because the original sampling scheme was not randomized or random-stratified over space and time, in the present analysis, only fish sampled in years 1981, 1983, 1984, and 1985 and in ICES subdivisions VIIg and VIIh were considered in order to 'rebalance' the sampling design. This resulted in a total of 3271 stomachs sampled, i.e. 829 for Atlantic cod 24-116 cm in length, 403 for haddock $24-83 \mathrm{~cm}$ in length, 682 for hake $25-95 \mathrm{~cm}$ in length, 749 for megrim $20-63 \mathrm{~cm}$ in length and 608 for whiting 20-60 cm in length. Despite 'rebalancing' sample sizes varied from year to year and between subdivisions (Table I).

\subsection{Prey trophic levels}

Stable isotope methods rely on the consistent enrichment of the stable nitrogen isotope, ${ }^{15} \mathrm{~N}(3.4$ \pm 0.3 per mil), between prey and predator (Minagawa \& Wada, 1984; Owens, 1987), allowing its use as a measure of an organism's continuous trophic position. Mean $T_{L}$ values of prey were extracted from a literature review of stable isotopes in the North Sea, Celtic Sea and Bay of Biscay (Jennings et al., 2002a,b; Pinnegar et al., 2002; Le Loc'h, 2004). When the $T_{L}$-size relationship was available (Jennings et al., 2002a) $T_{L} S$ assigned to fish prey were estimated corresponding to the median prey length of fish predators (Pinnegar et al., 2003). For prey identified at a broad taxonomic group level, the mean $T_{L}$ was calculated as the arithmetic mean of the values obtained from isotopic ratios for species belonging to this group. 'Cnidarians' were assigned the mean $T_{L}\left(T_{L}=2.5\right)$ value available in FishBase (http://www.fishbase.org; Froese \& Pauly, 2005) because no information was available for this group based on stable isotope methods.

The impact of the level of taxonomic resolution on estimates of predator $T_{L}$ was investigated replacing the $T_{L}$ of each prey by the $T_{L}$ of their broad taxonomic group level, i.e. cephalopod, cnidarian, crustacean, echinoderm, fish, mollusc (other than cephalopod) and polychaete. Sensitivity of predator $T_{L} S$ to prey $T_{L} S$ was also analysed based on $T_{L}$ values extracted from the FishBase database (www.fishbase.org; Froese \& Pauly, 2005). Non-parametric Wilcoxon MannWhitney tests were performed in both cases to analyse differences between $T_{L}$ distributions.

\subsection{Predator trophic levels and omnivory}

The $T_{L}$ of each individual sampled was calculated as the sum of its prey $T_{L}$, weighted by their relative importance in the stomach following Adams et al. (1983): 
$T_{L j l}=1+\sum_{i=1}^{n_{j l}} \rho_{i j l} \times \overline{T_{L i}}$

where $\rho_{\mathrm{ijl}}$ represents the relative biomass of prey $\mathrm{i}$ in the stomach of individual $\mathrm{I}$ of predator species $\mathrm{j}$, i.e. the relative weight of food $\mathrm{i}$ in the stomach, $\mathrm{n}_{\mathrm{jl}}$ is the number of prey in the stomach of individual I of predator species $j$ and $\overline{T_{L i}}$ is the mean $T_{L}$ of prey $i$.

$T_{L} S$ estimated for the five predator species of interest were compared on the one hand with values estimated by stable isotope methods in the Celtic Sea and in the North Sea (Pinnegar et al., 2002; Jennings et al., 2002a) and on the other hand with values aavailable in different areas of the world extracted from the FishBase database (http://www.fishbase.org; Froese \& Pauly, 2005).

Omnivory indices $\left(\mathrm{O}_{1}\right)$ of each individual sampled were also computed following Christensen \& Pauly (1992):

$O_{I j l}=\sum_{j=1}^{n_{j l}} \rho_{i j l} \times\left(T_{L i j l}-T_{L j l}\right)^{2}$

where $T_{L j}$ is the predator $T_{L}$ computed from equation (1). $O_{\text {I }}$ describes the range of $T_{L} S$ consumed and weights each prey item by its relative biomass in the stomach. The square root of $O_{1}$ has been proposed as a preliminary estimate of the standard deviation of $T_{L}$ (Christensen \& Pauly, 1992). Non-parametric Wilcoxon Mann-Whitney tests were performed to analyse differences between $\mathrm{O}$, distributions.

\subsection{Identifying sources of variability in trophic level values}

Generalized additive models (GAMs) were used to investigate the variability of $T_{L}$ over space and time and according to predator length. GAMs are non-parametric generalizations of multiple linear regressions (Hastie \& Tibschirani, 1990). In particular, GAM fitting methods do not rely on a rigid parametric shape, expressing the dependence between the response variable and the covariates, but on local smoothers. Individual predator $T_{L} S$ computed from equation (1) were modeled as a function of year, ICES subdivision, season and predator length. ICES subdivision was used to represent distinct areas assumed to characterize various types of habitat where prey availability changes. Season was modeled as a factor, i.e. winter, spring, summer, and autumn, and predator length (in $\mathrm{cm}$ ) as a continuous variable. Interaction effects were tested when possible. The general form of the model fitted for each predator species $\mathrm{j}$ and without interaction was then:

$T_{L j}=S_{j}($ length)+year+subdivision+season

where $T_{L}$ is the trophic level and $s_{j}()$ represents a smooth function (regression spline) for species j. Model fitting and automatic selection of the degrees of freedom for the regression splines, were performed using the generalized cross-validation method based on minimising the jackknifed squared prediction error in the mgcv package in R (R Development Core Team, 2007) as described in Wood \& Augustin (2002). The assumption of Gaussian error distributions was checked through the residuals. Selection of the 'best' model was based upon the Akaike information criterion (AIC). For each species, the AIC and percentage of deviance explained by each factor and covariate kept in the 'best' model were also given. The residuals in each GAM were used as a measure of $T_{L}$ intra-population variability. 


\section{Results}

\subsection{Trophic position in the Celtic sea}

The distributions of estimated individual $T_{L}$ values were rather asymmetric for all predator species (Fig. 2). All five species exhibited a range of $T_{L} S$ in the size range sampled: 3.81-5.88 for Atlantic cod, 3.50-5.95 for haddock, 4.02-6.08 for hake, 3.88-5.95 for megrim, and 3.99-5.95 for whiting. $T_{L}$ values estimated in the present study showed that the five species had a high position in the food web, the highest value of mean $T_{L}$ being 5.27 for whiting (Fig 3). $T_{L}$ standard deviations were relatively similar for the five species, the values ranging from 0.44 for Atlantic cod to 0.69 for hake (Fig. 3).

Estimated mean $T_{L}$ for the five predator species were higher than those available from FishBase (Fig. 3). $T_{L}$ estimates were also higher than values estimated from stable isotope methods in the Celtic Sea except for whiting (Fig. 3). The discrepancy was particularly important for haddock, hake and megrim with differences in $T_{L}$ values close or higher than $1 T_{L}$, i.e. $0.88,0.73$ and 1.09 respectively. Differences were less marked with $T_{L}$ estimated from stable isotope methods in the North Sea (Fig. 3).

\subsection{Sensitivity of trophic level estimates}

The level of taxonomic resolution used for prey had impacts on estimates of predator $T_{L}$ (Fig. $4 a$ ). Predator $T_{L} S$ based on prey groups were significantly lower than $T_{L} S$ based on a high taxonomic resolution for Atlantic cod $(P<0.001)$, megrim $(P<0.01)$, and whiting $(P<0.001)$ and significantly higher for hake $(P<0.001)$. Although significant, the differences between mean estimates of $T_{L}$ were small, i.e. less than 0.1 for Atlantic cod and hake, 0.12 and 0.35 for megrim and whiting respectively. Estimates of the $T_{L}$ of haddock were not modified by a decrease in the level of prey taxonomic resolution. By contrast, standard deviations of the $T_{L}$ were strongly modified and significantly higher for the 5 species when considering a high level of taxonomic resolution.

Values of $T_{L}$ assigned to the prey strongly affected estimates of predator $T_{L}$ (Fig. 4b). Predator $T_{L}$ based on prey $T_{L}$ derived from FishBase were significantly lower than $T_{L}$ estimates based on $T_{L} S$ derived from stable isotope methods $(P<0.001)$. These results show that prey $T_{L} S$ are important to estimate mean values of predator $T_{L}$ and that the level of resolution attained during stomach content analysis is essential for analysis of $T_{L}$ variability.

\subsection{Modelling trophic level variability}

The covariates explaining $T_{L}$ varied between species (Table II). The total deviance explained by the 'best' models was high for hake and megrim, $43.3 \%$ and $26.1 \%$ respectively, while it was $13.1 \%, 11.3 \%$, and $5.9 \%$ for whiting, haddock, and Atlantic cod respectively (Table II). Comparison between the deviance of the 'best' models and the deviance explained by the different covariates or factors individually showed that there were confounded effects, particularly for hake and megrim.

Considering the 'best' model, significant year and season effects were found for all species except Atlantic cod (Table II). This indicated interannual and seasonal variations in $T_{L}$ due to changes in types or relative proportions of prey consumed. Year and season effects differed between species. For instance, haddock showed estimates of $T_{L}$ higher in subdivision VIlg in $1983\left(T_{L}=4.63\right)$ than in $1981\left(T_{L}=4.40\right)$ whereas hake showed an overall negative effect on $T_{L}$ in 1983 relative to $1981\left(-0.44 T_{L}\right)$ and the highest $T_{L}$ for hake was observed in spring 1985 in subdivision VIIh $\left(T_{L}=5.72\right)$. Year-to-year changes in species specific $T_{L}$ led to variations in the rank of their position occupied within the food web. For instance, megrim was the 'top-predator' in 
subdivision VIIg in spring 1983, followed by whiting, Atlantic cod, haddock and hake. As hake's $T_{L}$ increased from 1983 to 1985 and whiting and haddock's $T_{L} S$ decreased throughout this period, in spring 1985 hake occupied a higher position than haddock and Atlantic cod, and a similar position as whiting.

Subdivision effects were also found to vary between Celtic sea fish predators. The overall effect of subdivision VIIh was positive for hake $\left(+0.53 \mathrm{~T}_{\mathrm{L}}\right)$ and negative for megrim $\left(-0.34 \mathrm{~T}_{\mathrm{L}}\right)$ relative to their respective GAM intercepts.

A subdivision effect in interaction with year or season was found significant for haddock, hake and megrim. For hake, a positive effect was found in autumn 1981 in subdivision VIlg $\left(+0.14 \mathrm{~T}_{\mathrm{L}}\right.$ relative to spring) whereas a negative season effect was found for autumn in subdivision VIIh ($0.22 T_{L}$ relative to spring). For megrim, the 1985 effect was found positive $\left(+0.2 T_{L}\right)$ in subdivision VIIh whereas it was negative in subdivision VIlg. Hence, temporal changes in $T_{L} S$ for the Celtic Sea fish predators were not similar among habitats defined here by the ICES subdivisions.

Length was significant for all species except haddock. $T_{L}$ increased with body length for Atlantic cod and megrim, and for hake from a $50 \mathrm{~cm}$ length (Fig. 5). Maximum changes in $T_{L}$ predicted by the GAMs for the range of length observed were $+0.43,+0.45,+0.80$, and $-0.21 T_{L}$ for Atlantic cod, hake, megrim, and whiting respectively. For whiting, no clear relationship was found, though there might be an indication of a decreasing pattern of $T_{L}$ with length over the size range 30-60 $\mathrm{cm}$.

\subsection{Trophic level variability and omnivory index}

Overall GAM results showed that $T_{L}$ standard deviation reflected on the one hand $T_{L}$ variations due to differences in area or season, and on the other hand between-individual (intra-population) variations. $T_{L}$ intra-population variability, derived from GAM residuals, was higher for megrim and hake (0.47 and 0.40 respectively) than for haddock (0.37), and Atlantic cod and whiting that showed a similar value of 0.30 . Results on $T_{L}$ intra-population variability differed from information

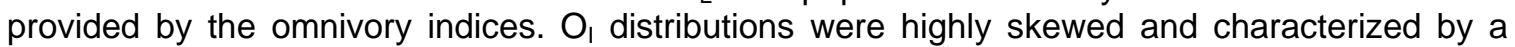
high proportion of 0 values corresponding to predators with only 1 type of prey in their stomach

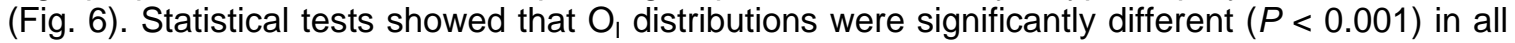
cases. Atlantic cod and haddock were the most omnivorous fish with mean values of $O_{\text {, equal to }}$ 0.054 and 0.041 , respectively. Hake and whiting were less omnivorous than Atlantic cod and haddock with mean $\mathrm{O}_{1} \mathrm{~S}$ of 0.017 and 0.012 respectively and megrim was the least omnivorous predator with a mean $\mathrm{O}_{1}$ of 0.008 .

Megrim's diet could then be characterized by a high between-individual variability of $T_{L} S$ with most of the individuals preying upon a small range of $T_{L} S$ at any given time. By contrast, Atlantic cod showed a lower $T_{L}$ variability but individual fish tended to consume on average a larger range of $T_{L} S$. In other terms, it was shown that Atlantic cod dietary niche width was mainly explained by generalist individuals all taking a wide range of food types (Type A generalization) whereas the larger dietary niche width for megrim resulted from individuals specializing on a different but narrow range of food types (Type $B$ generalization). Whiting displayed both a low $T_{L}$ variability and a low degree of omnivory, suggesting it was the most specialist species among the 5 predators. Haddock and hake appeared in intermediate positions in terms of both $T_{L}$ variability and omnivory.

\section{Discussion}

The $T_{L}$ of five major predator species of the Celtic Sea was estimated based on a database of food stomachs collected in the early 1980s and characterized by a high level of taxonomic 
resolution (> 150 prey taxa), and using mean values of prey $T_{L} S$ derived from a literature review of stable isotope analyses in adjacent seas. Predator $T_{L} S$ differed from values available in the literature or available from FishBase. The source of $T_{L}$ values assigned to the prey was found to potentially strongly affect predator $T_{L}$, depending on the species of interest. The level of taxonomic resolution of the prey did not greatly affect mean values of predator $T_{L} s$ but did affect $T_{L}$ variance, low resolution masking intra-population variability in $T_{L}$. In addition and assuming that stable isotopes correctly reflect prey $T_{L} S$, results provided evidence for high variability of $T_{L} S$ in space and time, and with length at the scale of ICES subdivision. The species specific variability of $T_{L}$ would be due to spatio-temporal variations in prey availability and/or in predator selectivity following ontogenetic changes (see below). Our findings also show that information available from $T_{L}$ variability and omnivory is complementary and adequate to describe ecological features of fish predators such as generalization type.

\subsection{Estimating trophic levels}

Although stomach content data are submitted to specific limits such as differential digestion rates and tissue digestibility (Hyslop, 1980), the use of stomach content data allowed us to investigate $T_{L}$ variability on relatively short time (season) and small spatial scales (ICES subdivision) as they reflect food present in the stomach over the digestion period. Prey digestion state could not be considered in the present analysis because information was generally missing. Gastric evacuation models might improve estimates of consumption rates but were not tested here (Andersen, 2001).

The level of taxonomic resolution reached during stomach content analysis depends on the objectives of the study and can be low for pragmatic (e.g. time restriction for identification) or ecological (e.g. rapid digestion) reasons. Effects of taxonomic resolution on mean $T_{L}$ values were rather low and differed between predator species. On the contrary, taxonomic resolution strongly affected $T_{L}$ standard deviations. Observed trophic levels as well as other major food web patterns have been shown to be sensitive to the level of resolution data (Martinez, 1991). In this context, high taxonomic resolution of prey, as in our dataset, is a major prerequisite for analysis of species specific $T_{L}$ variability.

Mean $T_{L} S$ assigned to prey in equation (1) also have a strong impact on predator $T_{L} S$ and are therefore of major concern for ecosystem analyses based on $T_{L}$-based indicators. It was assumed here that isotope values correctly characterise the $T_{L}$ of the prey animals although some studies have shown that they may vary with size due to ontogenetic changes (Hentschel, 1998). The use of mean values for prey $T_{L}$ constitutes the classic approach to estimate predator $T_{L}$ following equation (1) and the standard deviation of prey $T_{L} S$ were generally low in the samples of Pinnegar et al. (2002), Jennings et al. (2002b) and Le Loc'h (2004). Prey $T_{L} S$ used were thus considered as the best current information available to analyse the variability of predator $T_{L} S$. Using prey $T_{L} S$ derived from stable isotopes of nitrogen allowed us to avoid the use of default values for prey $T_{L} S$ currently used in FishBase except for cnidarians and allowed us to assign mean $T_{L}$ values for small invertebrate prey groups for which diets are generally poorly known. Application of stable isotope methods to estimate cnidarians $T_{L}$ in the European seas would allow better quantifying their $T_{L}$ for future analyses. In addition, the use of mean prey $T_{L} S$ provided by isotope methods seems consistent for the estimation of predator $T_{L} S$ because they integrate prey diet over a period ranging from a few months to one year, depending on the turn-over rate of the tissues (O'Reilly et al., 2002). Recent work has however suggested that the assumption of average enrichment of 3.4 per mil, may be problematic as isotopic fractionation can be impacted by feeding rate, nitrogen content of the food, excretion rate and assimilation efficiency (e.g. Olive et al., 2003). Such validation has however not been completed in a complex open sea food web and Post (2002) has shown using a comparative cross-system analysis that the mean fractionation of $\delta^{15} \mathrm{~N}$ is remarkably constant among trophic levels in many species. On the basis of the currently 'best' values of prey $T_{L}$ available, species specific $T_{L}$ estimates relevant at the scale of the Celtic Sea were thus provided. 
Predator $T_{L} S$ estimated in this study were generally higher than estimates obtained by Pinnegar et al. (2002) using stable isotopes. The differences between our estimates and $T_{L} S$ derived from $\delta^{15} \mathrm{~N}$ data are difficult to interpret regarding the assumptions made in both methods. Among other causes, this could be inherent to the nominal 'baseline' organisms with known $T_{L}$ used to estimate prey $T_{L} S$ in stable isotope analyses. If the 'baseline' is wrong then all values will be shifted upwards or downwards incorrectly. The low sample size used by Pinnegar et al. (2002), whose study mainly focused on large fishes, could also be responsible for the underestimation observed in predator $T_{L}$ estimates.

$T_{L} S$ estimated in the present analysis were higher than FishBase values. These differences can result both from the $T_{L} S$ assigned to the prey and to the predator size-range sampled. Prey $T_{L} S$ used were based on a review of stable isotope methods that showed that default values available for species groups from FishBase (bivalves, cephalopods, crustaceans, echinoderms and polychaetes) were always underestimated.

\subsection{Factors influencing trophic level variability}

$T_{L}$ values were found to vary with respect to different variables according to the predator species considered. Deviance explained by GAMs was the lowest for Atlantic cod and haddock that displayed the most omnivorous feeding strategy. This could suggest that spatio-temporal changes in prey abundance and composition in the ecosystem might affect omnivorous species less than more specialist predators.

ICES subdivision was used here to characterize distinct habitats described by differences in prey availability and/or composition. It was shown that $T_{L}$ could significantly vary at the scale of ICES subdivision for haddock, hake, and megrim. Atlantic cod did not show significant change in $T_{L}$ between ICES subdivisions although they are generalist predators that have been shown to display variations in diet according to area (du Buit, 1995; Hanson \& Chouinard, 2002; Link \& Garrison, 2002). The type A generalization (Van Valen, 1965) observed for Atlantic cod could explain that spatial variations in diet composition were not reflected in $T_{L}$ as Atlantic cod consumed a wide diversity of prey in each area of the Celtic Sea. No significant spatial effect on $T_{L}$ was found for whiting whereas they were found to show geographical differences in diet composition in the North Sea and the Sea of Marmara (Hislop et al., 1991; Artüz, 2005). In the Celtic Sea, whiting mainly consumed fish prey such as sprat (Sprattus sprattus), Trisopterus spp., and blue whiting (Micromesistius poutassou) that are distributed all over the area. This could explain the absence of variations in $T_{L}$ between ICES subdivisions. In operational terms for an $E A F$, showing significant spatial variations in $T_{L}$ for particular species emphasizes the need to consider ecosystem specific predator $T_{L}$. Considering spatialized $T_{L} S$ would seem of major importance for specialist predators with prey showing a limited geographic distribution.

Hake have been shown to display large seasonal diet variations in the Bay of Biscay (Guichet, 1995) but not in the Cantabrian Sea (Velasco \& Olaso, 1998). Major prey of hake, i.e. blue whiting (Micromesistius poutassou), mackerel (Scomber scombrus) and horse mackerel (Trachurus trachurus) were found to be consumed in accordance with their higher densities in the Celtic Sea (Pinnegar et al., 2003; Trenkel et al., 2005). Megrim has also been shown to consume more blue-whiting when this prey was at higher abundance in the environment (Pinnegar et al., 2003; Trenkel et al., 2005). Density related prey selection seems therefore to explain seasonal changes in $T_{L}$ for hake and megrim. For hake, the interaction effect between season and subdivision showed that seasonal changes in $T_{L}$ could vary according to area. The diet of whiting has also been shown to display seasonal variations, with some prey such as sandeel (Ammodytes spp.) being more prominent in whiting diets during the summer, which coincided with their peak abundance (Greenstreet et al., 1998).

The absence of a seasonal effect for haddock was not expected as different studies have evidenced considerable seasonal variation in their diet (Jiang \& Jorgensen, 1996, Greenstreet et al., 1998; Adlerstein et al., 2002). These variations might not be reflected in terms of $T_{L}$ for 
haddock as they are omnivorous fish and their diet is mostly composed of echinoderms, molluscs and polychaetes that were assigned similar $T_{L}$ values comprised between 3.0 and 3.4. This could indicate that although there are marked changes in the types of invertebrate prey targeted by haddock, these fishes may actually select prey with similar $T_{L} S$ (Deudero et al., 2004). Finally, the absence of seasonal effect for Atlantic cod could again be explained by the wide diversity of prey they consumed in the Celtic Sea.

The increase in $T_{L}$ for Atlantic cod is mainly explained by the increasing proportion of fish in their diet with age, although crustaceans always remain a major component in the food, even for older specimens (du Buit, 1995; Pinnegar et al., 2003). Hake are opportunistic consumers mostly piscivorous that do not seem to have a selective predatory behaviour (du Buit, 1996). Nevertheless, larger fish $\left(>50 \mathrm{~cm}\right.$ ) tend to target horse-mackerel (Trachurus spp.; $\mathrm{T}_{\mathrm{L}}=4.95$ ) and pilchard (Sardina pilchardus; $\left.T_{L}=3.59\right)$ whereas small predators exploit blue whiting $\left(T_{L}=3.14\right)$, Argentina spp. $\left(T_{L}=3.44\right)$ and Trisopterus spp. $\left(T_{L}=4.52\right)$ (Pinnegar et al., 2003; Mahé et al., 2007). This might be the reason for the increasing relationship between $T_{L}$ and size observed for hake larger than $50 \mathrm{~cm}$. Megrim was also found to show increasing $T_{L}$ with length with a plateau from $50 \mathrm{~cm}$ that is related to the increasing proportion of fish in their diet with length.

Changes in prey targeted with size is a well known phenomenon for marine fish predators and is mostly associated with increase in mouth size and improved swimming performance (Karpouzi \& Stergiou, 2003; Scharf et al., 2000). For hake and Atlantic cod, the fact that large predators continued to select small benthic prey of lower $T_{L}$ throughout their lives explained why the size- $T_{L}$ relationships were not as strong as shown in the North Sea (Jennings et al., 2002a). In this context, the weak interactions inherent to the large opportunism characterizing the Celtic Sea fish community (Trenkel et al., 2005) led here to a smaller variation in $T_{L}$ with length compared to the North Sea fish community.

Regarding haddock, it has been reported elsewhere that the proportion of fish in their diet increased as their size increased (Greenstreet et al., 1998). The absence of significant effect on $T_{L}$ is due to the similar range of fish prey $T_{L}$ consumed with increasing length of haddock. Variations in $T_{L}$ with length for whiting differ from the increasing $T_{L}$-size relationship observed by Jennings et al. (2002a) in the North Sea. The increase in $T_{L}$ from $20 \mathrm{~cm}$ to $30 \mathrm{~cm}$ whiting seems mainly due in our analysis to the switch from sprats $\left(T_{L}=4.28\right)$ to Trisopterus spp. $\left(T_{L}=4.52\right)$ in their diet as they grew. Such a switch has also been observed for whiting in the Moray Firth, NE Scotland, and could be linked to a change from pelagic to demersal habits as they grow older (Greenstreet et al., 1998). The progressive increase of blue whiting $\left(T_{L}=3.14\right)$ in the diet of whiting with length could explain the decreasing trend in $T_{L}$ from $30 \mathrm{~cm}$ (Fig.5).

\subsection{Trophic level variability and omnivory}

Our results show that mean values of $T_{L}$ mask a high intra-population $T_{L}$ variability that can differ between species. In addition, $O_{I}$ appears to be a bad proxy for $T_{L}$ variability therefore its square root should not be a good estimate of the standard error of $T_{L}$ as proposed by Christensen and Pauly (1992). O,S however provide information regarding the range of $T_{L} S$ targeted by individual predators and seem very useful to estimate the trophic niche width of a population. In complement with $T_{L}$ variability derived from GAM residuals, $O_{S} S$ were used to identify generalization type (Van Valen, 1965) and separate between within-individual and betweenindividual components contributing to niche width. The assessment of feeding strategy and measure of individual-level niche variation is a major issue both in theoretical and applied ecology (Amundsen et al., 1996; Bolnick et al., 2003; Bearhop et al., 2004) and combining information on $T_{L}$ variability and omnivory seems a promising approach to address such questions.

Quantifying $T_{L}$ variability is also useful for estimating ecosystem indicators and improving trophodynamic models. For instance, the weighted smoothing technique adopted to spread biomass or catches of a species along a range of fractional $T_{L}$ in trophic spectra assumes constant and symmetrical distribution of $\mathrm{T}_{\mathrm{L}}$ among species (Gascuel et al., 2005). Here our 
results suggest that the distribution of individual $T_{L}$ is neither symmetric nor constant between species and that the range of $0.7 \mathrm{~T}_{\mathrm{L}}$ used by Gascuel et al. (2005) underestimates $T_{L}$ variability observed for Celtic Sea fish predators, the 95\% reference range being comprised between 1.6 for Atlantic cod and 2.0 for haddock. In the same way, application of trophodynamic models based on $T_{L}$ to real case-studies (Chassot et al., 2005; Gascuel, 2005) requires information on species $T_{L}$ distribution to spread the biomass among trophic groups.

We are grateful to $\mathrm{M}$. H. du Buit for collecting and analysing all stomach contents. We thank A. Colomb, Y. -M. Bozec and E. Rivot (Agrocampus) for stimulating and fruitful discussions on the variability of trophic level and J. K. Pinnegar (CEFAS) for insightful comments on an earlier version of the manuscript. J. Guitton and S. Bonhommeau (Agrocampus) helped with map drawing. We also thank A. Caskenette (DFO) for English corrections. Anonymous reviewers helped to improve the manuscript. This work was financed by the EU funded RTD project QLRT2000-02277 "PECHDEV".

\section{References}

Adams, S. M., Kimmel, B. L. \& Ploskey, G. R. (1983). Sources of organic matter for reservoir fish production: a trophic-dynamics analysis. Canadian Journal of Fisheries and Aquatic Sciences 40, 1480-1495.

Adlerstein, S. A. \& Welleman, H. C. (2000). Diel variation of stomach contents of North Sea cod (Gadus morhua) during a 24-h fishing survey: an analysis using generalized additive models. Canadian Journal of Fisheries and Aquatic Sciences 57, 2363-2367.

Adlerstein, S. A, Temming, A. \& Mergardt, N. (2002). Comparison of stomach contents of haddock (Melanogrammus aeglefinus) from the 1981 and 1991 North Sea International Stomach Sampling Projects. ICES Journal of Marine Science 59, 497-515.

Albert, O. T. (1995). Diel changes in food and feeding of small gadoids on a coastal bank. ICES Journal of Marine Science 52, 873-885.

Amundsen, P. -A., Gabler, H. -M., \& Staldvik, F. J. (1996). A new approach to graphical analysis of feeding strategy from stomach contents data-modification of the Costello (1990) method. Journal of Fish Biology 48, 607-614. doi: 10.1111/j.1095-8649.1996.tb01455.x

Andersen, N. G. (2001). A gastric evacuation model for three predatory gadoids and implications of using pooled field data of stomach contents to estimate food rations. Journal of Fish Biology 59, 1198-1217. doi:10.1111/j.1095-8649.2001.tb00186.x

Artüz, M. L. (2005). The diet and food consumption of whiting Merlangius merlangus merlangus (Linné) 1758 in the Sea of Marmara. Hidrobiologica 1, 23-26.

Bearhop, S., Adams, C. E., Waldron, S., Fuller, R. A. \& Macleod, H. (2004). Determining trophic niche width: a novel approach using stable isotope analysis. Journal of Animal Ecology 73, 10071012.

Bolnick, D. I., Svanbäck, R., Fordyce, J. A., Yang, L. H., Davis, J. M., Hulsey, C. D., \& Forister, M. L. (2003). The ecology of individuals: incidence and implications of individual specialization. American Naturalist 161, 1-28.

Cabral, H. N. \& Murta, A. G. (2002). The diet of blue whiting, hake, horse mackerel and mackerel off Portugal. Journal of Applied Ichthyology 18, 14-23. doi: 10.1046/j.1439-0426.2002.00297.x 
Carpentieri, P., Colloca, F., Cardinale, M., Belluscio, A. \& Ardizzone, G. D. (2005). Feeding habits of European hake (Merluccius merluccius) in the central Mediterranean Sea. Fishery Bulletin 103, 411-416.

Chassot, E., Gascuel, D. \& Colomb, A. (2005). Impact of trophic interactions on production functions and on the ecosystem response to fishing: a simulation approach. Aquatic Living resources 18, 1-13.

Christensen, V. \& Pauly, D. (1992). ECOPATH II - a software for balancing steady-state ecosystem models and calculating network characteristics. Ecological Modelling 61, 169-185.

Cury, P. M., Shannon, L. J., Roux, J. P., Daskalov, G. M., Jarre, A., Moloney, C. L. \& Pauly, D. (2005). Trophodynamic indicators for an ecosystem approach to fisheries. ICES Journal of Marine Science 62, 430-442.

Deudero, S., Pinnegar, J. K., Polunin, N. V. C., Morey, G., \& Morales-Nin, B. (2004). Spatial variation and ontogenic shifts in the isotopic composition of Mediterranean littoral fishes. Marine Biology 145, 971-981.

du Buit, M. H. (1982). Essai d'évaluation de la prédation de quelques téléostéens en Mer Celtique. Journal du Conseil International pour l'Exploration de la Mer 40, 37-46.

du Buit, M. H. (1992). Alimentation de la Cardine, Lepidorhombus whiffiagonis en Mer Celtique. Cahiers de Biologie Marine 33, 501-514.

du Buit, M. H. (1995). Food and feeding of cod (Gadus morhua L.) in the Celtic Sea. Fisheries Research 22, 227-241.

du Buit, M. H. (1996). Diet of hake (Merluccius merluccius) in the Celtic Sea. Fisheries Research 28, 381-394.

Froese, R. \& Pauly, D. (2005). Fishbase 2005, Concepts, design and data sources. ICLARM, Los Baños, Laguna, Philippines.

Garcia, S. M., Zerbi, A., Do Chi, T. \& Lasserre, G. (2003). The ecosystem approach to fisheries. Issues, terminology, principles, institutional foundations, implementation and outlook. FAO, Rome, Italy.

Gascuel, D. (2005). The trophic-level based model: a theoretical approach of fishing effects on marine ecosystems. Ecological Modelling 189, 315-332.

Gascuel, D., Bozec, Y. -M., Chassot, E., Colomb, A. \& Laurans, M. (2005). The trophic spectrum: theory and application as an ecosystem indicator. ICES Journal of Marine Science 62, 443-452.

Greenstreet, S. P. R., Bryant, A. D., Broekhuizen, N., Hall, S. J. \& Heath, M. R. (1997). Seasonal variation in the consumption of food by fish in the North Sea and implications for food web dynamics. ICES Journal of Marine Science 54, 243-266.

Greenstreet, S. P. R., McMillan, J. A. \& Armstrong, E. (1998). Seasonal variation in the importance of pelagic fish in the diet of piscivorous fish in the Moray Firth, NE Scotland: a response to variation in prey abundance? ICES Journal of Marine Science 55, 121-33.

Guichet, R. (1995). The diet of European hake (Merluccius merluccius) in the northern part of the Bay of Biscay. ICES Journal of Marine Science 52, 21-31. 
Hanson, J. M. \& Chouinard, G. A. (2002). Diet of Atlantic cod in the southern Gulf of St Lawrence as an index of ecosystem change, 1959-2000. Journal of Fish Biology 60, 902-922. doi: 10.1006/jfbi.2002.1893

Hastie, T. \& Tibshirani, R. (1990). Generalized Additive Models. Chapman \& Hall, London, UK.

Hentschel, B. (1998). Intraspecific variations in $\delta^{13} \mathrm{C}$ indicate ontogenetic diet changes in depositfeeding polychaetes. Ecology 79, 1357-1370.

Hislop, J. R. G., Robb, A. P., Bell, M. A. \& Armstrong, D. W. (1991). The diet and food consumption of whiting (Merlangius merlangus) in the North Sea. ICES Journal of Marine Science 48, 139-156.

Hop, H., Gjosaeter, J. \& Danielssen, D. S. (1992). Seasonal feeding ecology of cod (Gadus morhua L.) on the Norwegian Skagerrak coast. ICES Journal of Marine Science 49, 453-461.

Hyslop, E. J. (1980). Stomach contents analysis - a review of methods and their application. Journal of Fish Biology 17, 411-429. doi: 10.1111/j.1095-8649.1980.tb02775.x

Jennings, S., Greenstreet, S., Hill, L., Piet, G., Pinnegar, J. K. \& Warr, K. J. (2002a). Long-term trends in the trophic structure of the North Sea fish community: evidence from stable-isotope analysis, size spectra and community metrics. Marine Biology 141, 1085-1097.

Jennings, S., Pinnegar, J. K., Polunin, N. V. C. \& Warr, K. J. (2002b). Linking size-based and trophic analyses of benthic community structure. Marine Ecology Progress Series 226, 77-85.

Jiang, W. \& Jorgensen, T. (1996). The diet of haddock (Melanogrammus aeglefinus L.) in the Barents Sea during the period 1984-1991. ICES Journal of Marine Science 53, 11-21.

Karpouzi, V. S. \& Stergiou, K.I. (2003). The relationships between mouth size and shape and body length for 18 species of marine fishes and their trophic implications. Journal of Fish Biology 62, 1353-1365. doi: 10.1046/j.1095-8649.2003.00118.x

Le Loc'h, F. (2004). Structure, fonctionnement, évolution des communautés benthiques des fonds meubles exploités du plateau continental Nord Gascogne. Thèse pour l'obtention du diplôme de Docteur de I'Université de Bretagne Occidentale, spécialité Océanologie Biologique, Brest, France.

Lindeman, R. L. (1942). The trophic-dynamic aspect of ecology. Ecology 23, 399-418.

Link, J. S. \& Garrison, L. P. (2002). Trophic ecology of Atlantic cod Gadus morhua on the northeast US continental shelf. Marine Ecology Progress Series 227, 109-123.

Mahé, K., Amara, R., Bryckaert, T., Kacher, M. \& Brylinski J. M. (2007). Ontogenetic and spatial variation in the diet of hake (Merluccius merluccius) in the Bay of Biscay and the Celtic Sea. ICES Journal of Marine Science 64, 1210-1219.

Martinez, N. D. (1991). Artifacts or attributes? Effects of resolution on the Little Rock Lake food web, Ecological Monographs 61, 367-392.

Mérigoux, S. \& Ponton, D. (1998). Body shape, diet and ontogenetic diet shifts in young fish of the Sinnamary River, French Guiana, South America. Journal of Fish Biology 52, 556-569. doi: 10.1111/j.1095-8649.1998.tb02017.x 
Minagawa, M. \& Wada, E. (1984). Stepwise enrichment of ${ }^{15} \mathrm{~N}$ along food chains: further evidence and the relation between ${ }^{15} \mathrm{~N}$ and animal age. Geochimica et Cosmochimica Acta 48, $1135-1140$.

Morte, S., Redon, M. J. \& Sanz-Brau, A. (1999). Feeding ecology of two megrims Lepidorhombus boscii and Lepidorhombus whiffiagonis in the western Mediterranean (Gulf of Valencia, Spain). Journal of the Marine Biological Association of the United Kingdom 79, 161-169.

Olive, P .J. W., Pinnegar, J. K., Polunin, N. V. C., Richards, G. \& Welch, R. (2003). Isotope trophic-step fractionation: a dynamic equilibrium model. Journal of Animal Ecology 72, 608-617. doi: 10.1046/j.1365-2656.2003.00730.x

O'Reilly, C. M., Hecky, R. E., Cohen, A. S. \& Plisnier, P. -D. (2002). Interpreting stable isotopes in food webs: recognizing the role of time averaging at different trophic levels. Limnology and Oceanography 47, 306-309.

Owens, N. J. P. (1987). Natural variations in ${ }^{15} \mathrm{~N}$ in the marine environment. Advances in Marine Biology 24, 389-451.

Pauly, D., Christensen, V., Dalsgaard, J., Froese, R. \& Torres, F. J. (1998). Fishing down marine food webs. Science 279, 860-863.

Pauly, D., Christensen, V. \& Walters, C. (2000). Ecopath, Ecosim, and Ecospace as tools for evaluating ecosystem impact of fisheries. ICES Journal of Marine Science 57, 697-706.

Pauly, D. \& Watson, R. (2005). Background and interpretation of the 'Marine Trophic Index' as a measure of biodiversity. Philosophical Transactions of the Royal Society of London Biological Series 360, 415-423.

Pinnegar J. K., Jennings, S., O'Brien, C. M. \& Polunin N. V. C. (2002). Long-term changes in the trophic level of the Celtic Sea fish community and fish market price distribution. Journal of Applied Ecology 39, 377-390. doi: 10.1046/j.1365-2664.2002.00723.x

Pinnegar, J. K., Trenkel, V. M., Tidd, A. N., Dawson, W. A. \& du Buit, M. H. (2003). Does diet in Celtic Sea fishes reflect prey availability? Journal of Fish Biology 63, 197-212. doi: 10.1111/j.1095-8649.2003.00204.x

Post, D. M. (2002). Using stable isotopes to estimate trophic position: models, methods, and assumptions. Ecology 83, 703-718.

R Development Core Team. (2007). R: a language and environment for statistical computing. R Foundation for statistical computing, Vienna, Austria.

Scharf, F. S., Juanes, F. \& Rountree, R. A. (2000). Predator size-prey relationships of marine fish predators: interspecific variation and effects of ontogeny and body size on trophic niche breadth. Marine Ecology Progress Series 208, 229-248.

Sih, A. \& Christensen, B. (2001). Optimal diet theory: when does it work, and when and why does it fail? Animal Behaviour 61, 379-390.

Stergiou, K. I. \& Karpouzi, V. S. (2002). Feeding habits and trophic levels of Mediterranean fish. Reviews in Fish Biology and Fisheries 11, 217-254.

Stergiou, K. I., Moutopoulos, D. K., Casal, H. J. A. \& Erzini, K. (2007). Trophic signatures of small-scale fishing gears: implications for conservation and management. Marine Ecology Progress Series 333, 117-128. 
Trenkel, V. M., Pinnegar, J. K., Dawson, W. A., du Buit, M. H. \& Tidd, A. N. (2005). Spatial and temporal structure of predator-prey relationships in the Celtic Sea fish community. Marine Ecology Progress Series 299, 257-268.

Van Valen, L. (1965). Morphological variation and width of ecological niche. American Naturalist 99, 377-389.

Velasco, F. \& Olaso, I. (1998). European hake Merluccius merluccius (L., 1758) feeding in the Cantabrian Sea: seasonal, bathymetric and length variations. Fisheries Research 38, 33-44.

Williams, R. J. \& Martinez, N. D. (2004). Limits to trophic levels and omnivory in complex food webs: theory and data. American Naturalist 163, 458-468.

Wood, S. N. \& Augustin, N. H. (2002). GAMs with integrated model selection using penalized regression splines and applications to environmental modelling. Ecological Modelling 157, 157177. 
Table I. Spatial and temporal coverage of the stomach data analysed

\begin{tabular}{|c|c|c|c|c|c|c|}
\hline \multirow[b]{2}{*}{ Year } & \multirow[b]{2}{*}{ Division } & $\begin{array}{c}\text { Gadus } \\
\text { morhua }\end{array}$ & $\begin{array}{c}\text { Melanogrammus } \\
\text { aeglefinus }\end{array}$ & $\begin{array}{l}\text { Merluccius } \\
\text { merluccius }\end{array}$ & $\begin{array}{c}\text { Lepidorhombus } \\
\text { whiffiagonis }\end{array}$ & $\begin{array}{l}\text { Merlangius } \\
\text { merlangus }\end{array}$ \\
\hline & & & & & & \\
\hline 1981 & VIIg & 29 & 14 & 52 & 13 & 31 \\
\hline 1983 & VIIh & 2 & 53 & 165 & 164 & 60 \\
\hline \multirow[t]{2}{*}{1984} & VIIg & 640 & 224 & - & 69 & 399 \\
\hline & VIIh & 67 & 66 & 166 & 118 & 52 \\
\hline \multirow[t]{2}{*}{1985} & VIIg & 91 & 41 & 221 & 252 & 66 \\
\hline & VIIh & - & 5 & 83 & 133 & - \\
\hline
\end{tabular}


Table II. 'Best' models (i.e. smallest Akaike information criterion; AIC) for explaining $T_{L}$ of predator species in the Celtic Sea. Explanatory variables, deviance explained, and AIC value for each species 'best' GAM model are given. Significance level is indicated by asterixes: ${ }^{*} P<0.05$; ${ }^{* *} P<0.01 ; * * * P<0.001$. Degrees of freedom (df), deviance explained, and AIC are also given for GAM models with each significant variable of the 'best' model considered individually

\begin{tabular}{|c|c|c|c|c|c|}
\hline Species & Variables & $\mathrm{df}$ & Significance & Deviance & $\mathrm{AIC}$ \\
\hline \multirow[t]{2}{*}{ Cod } & $\mathrm{T}_{L}=\mathrm{s}($ length $)$ & & & $5.9 \%$ & 828.6 \\
\hline & $\mathrm{s}($ length $)$ & 4.0 & $* * *$ & $5.9 \%$ & 828.6 \\
\hline \multirow[t]{4}{*}{ Haddock } & \multicolumn{3}{|c|}{$\mathrm{T}_{L}=$ year $\times$ subdivision } & $11.3 \%$ & 576.7 \\
\hline & year & 3 & $* * *$ & $9.9 \%$ & 579.2 \\
\hline & subdivision & 1 & ns & $0.8 \%$ & 613.9 \\
\hline & year*subdivision & 5 & $* * *$ & $11.3 \%$ & 576.7 \\
\hline \multirow[t]{6}{*}{ Hake } & \multicolumn{3}{|c|}{$\mathrm{T}_{L}=\mathrm{s}($ length $)+$ year + season $\times$ subdivision } & $42.3 \%$ & 1065.7 \\
\hline & s(length) & 6.0 & $* * *$ & $16.6 \%$ & 1312.7 \\
\hline & year & 3 & $* * *$ & $28.4 \%$ & 1202.4 \\
\hline & season & 1 & $* * *$ & $1.8 \%$ & 1413.8 \\
\hline & subdivision & 1 & $* * *$ & $21.7 \%$ & 1259.8 \\
\hline & season* ${ }^{*}$ subdivision & 3 & $* * *$ & $27.2 \%$ & 1213.8 \\
\hline \multirow[t]{5}{*}{ Megrim } & \multicolumn{3}{|c|}{$\mathrm{T}_{L}=\mathrm{s}($ length $)+$ year $\times$ subdivision + season } & $26.1 \%$ & 1246.2 \\
\hline & s(length) & 8.2 & $* * *$ & $7.7 \%$ & 1409.5 \\
\hline & year & 3 & $* * *$ & $4.0 \%$ & 1428.4 \\
\hline & subdivision & 1 & $* * *$ & $2.7 \%$ & 1434.8 \\
\hline & season & 2 & $* * *$ & $3.9 \%$ & 1427.6 \\
\hline \multirow[t]{4}{*}{ Whiting } & \multicolumn{3}{|c|}{$\mathrm{T}_{L}=\mathrm{s}($ length $)+$ year + season } & $13.1 \%$ & 728.3 \\
\hline & s(length) & 5.6 & $*$ & $2.8 \%$ & 785.7 \\
\hline & year & 3 & $* * *$ & $8.0 \%$ & 746.6 \\
\hline & season & 3 & $* * *$ & $4.4 \%$ & 770.4 \\
\hline
\end{tabular}




\section{Figure captions}

Figure 1. Location of the ICES subdivisions (VIIf,g,h,j) of the Celtic Sea

Figure 2. Density histograms for all individual trophic levels $\left(\mathrm{T}_{\mathrm{L}}\right)$ analysed of the Celtic Sea fish predators

Figure 3. Comparison of trophic level for the five species of interest as estimated in the present study ( $\square$, derived from stable isotopes of nitrogen in the celtic Sea (E- $(\underline{\underline{\underline{Z}})})$ and the North Sea ( $\square$ ), and extracted from the FishBase database $(\square)$. Cod = Atlantic cod; Had $=$ Haddock; Hke = Hake; Meg = Megrim; Whg = Whiting. Vertical lines indicate standard deviation when available

Figure 4. Comparison of trophic levels (mean \pm standard deviation) estimated for the Celtic Sea fish predators: (a) Different levels of taxonomic resolution for the prey: high resolution in abscissa and low resolution (broad taxonomic group) in ordinate; (b) Different sources of prey $\mathrm{T}_{\mathrm{L}} \mathrm{s}$ : prey $\mathrm{T}_{\mathrm{L}} \mathrm{S}$ derived from stable isotopes in abscissa and extracted from the FishBase database in ordinate Cod = Atlantic cod; Had = Haddock; Hke = Hake; Meg = Megrim; Whg = Whiting

Figure 5. Trophic level $\left(T_{L}\right)$ as a function of length (generalized additive model GAM, gaussian family, identity link function). No significant effect of length on the $\mathrm{T}_{\mathrm{L}}$ of haddock was detected. Whiskers on the abscissa axis indicate data presence

Figure 6. Boxplots for all individual omnivory indices $\left(\mathrm{O}_{\mathrm{I}}\right)$ analysed of the Celtic Sea fish predators 

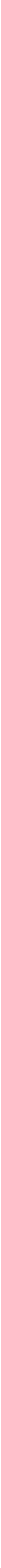


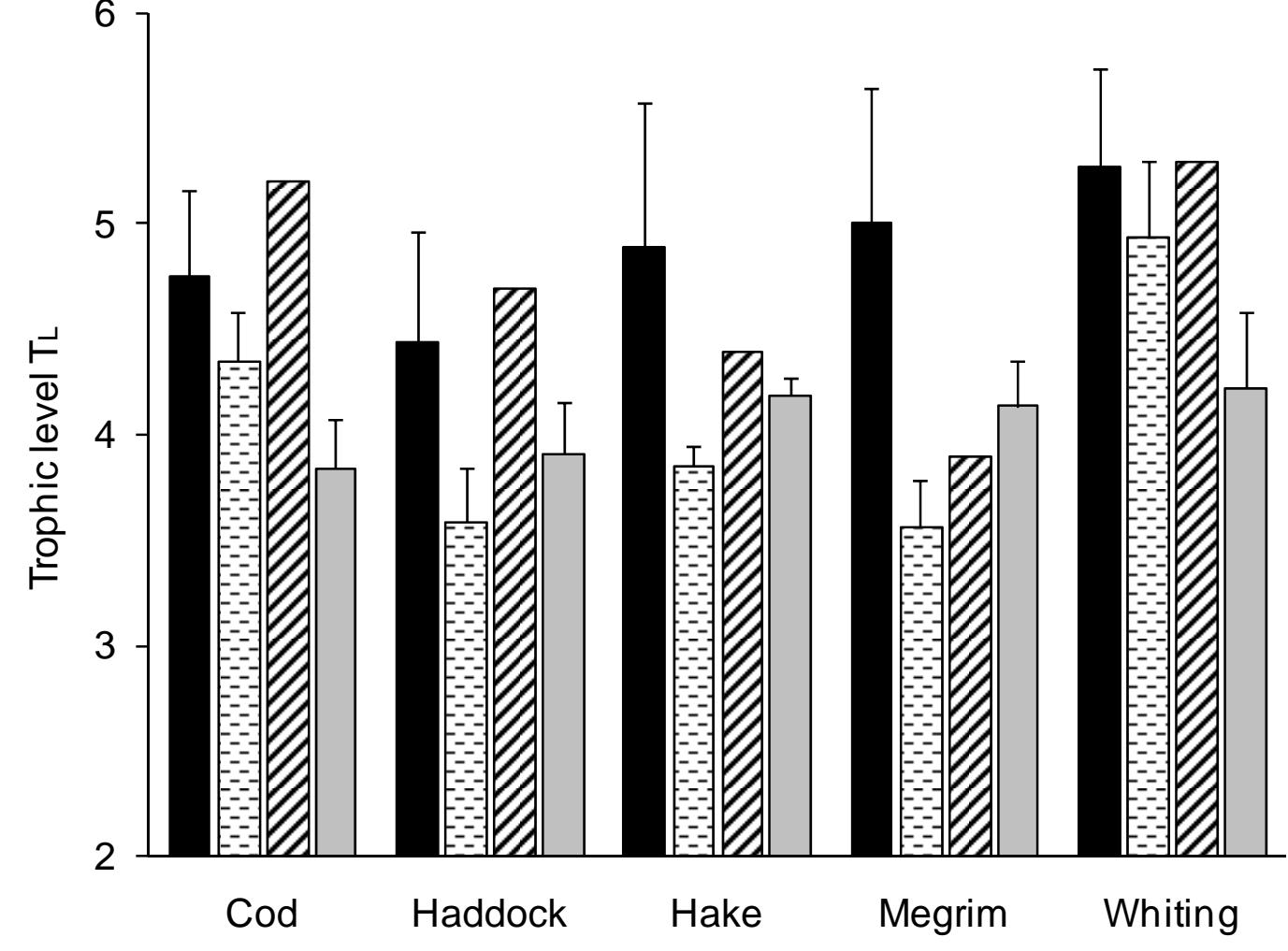

Figure 3 
(a)

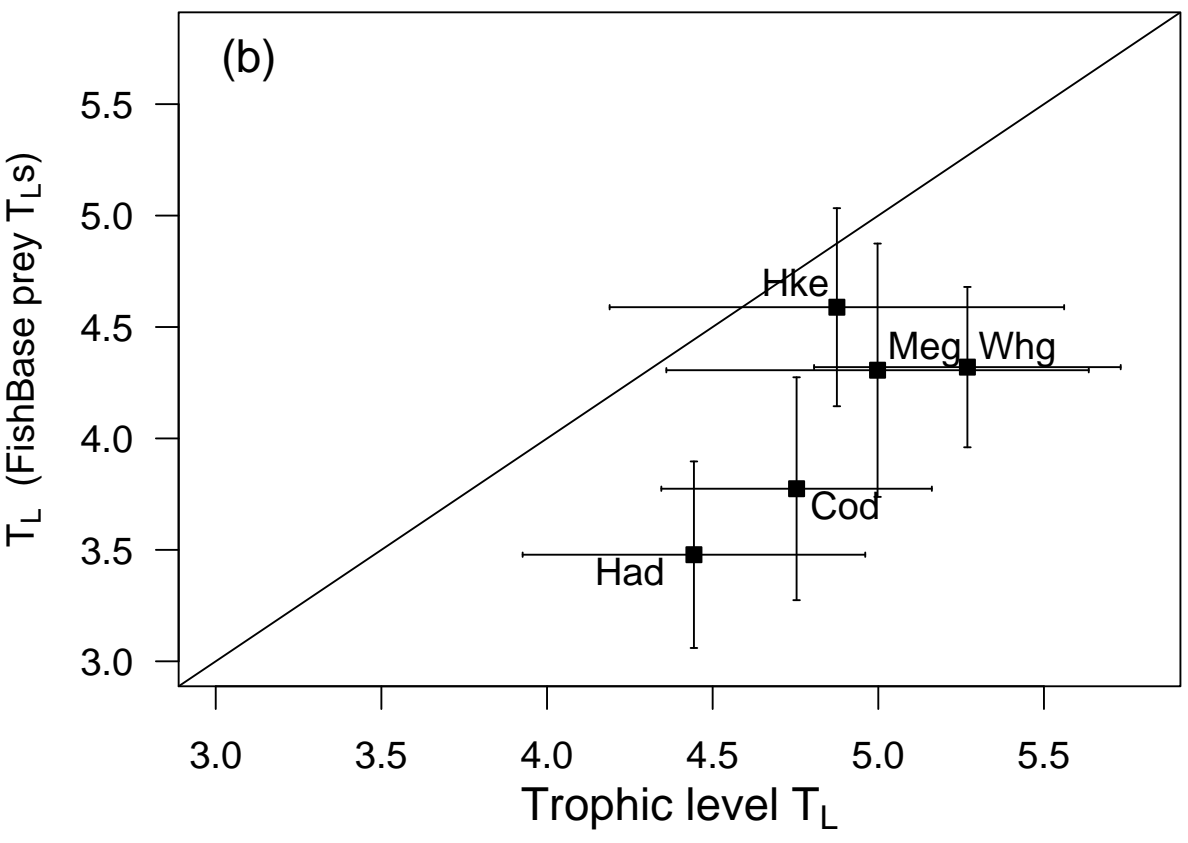

Figure 4: 


\section{Cod}

$$
(n=829)
$$

Haddock
$(n=403)$
Hake
$(n=682)$

Megrim

$$
(n=749)
$$

Whiting

$$
(n=608)
$$
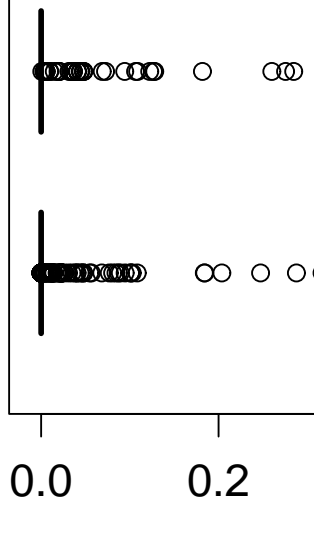

Omnivory index $\mathrm{O}_{\mathrm{I}}$

Figure 6: 